\title{
Formação de Psicólogos em Residência Multiprofissional: Transdisciplinaridade, Núcleo Profissional e Saúde Mental
}

\author{
Education For Psychologists In Multi-Professional Residencies: \\ Transdisciplinarity, Professional Body, And Mental Health \\ Formación De Psicólogos En Residencia Multiprofesional: \\ Transdisciplinariedad, Núcleo Profesional Y Salud Mental.
}

Mônica Lima \&

Lívia Santos

Universidade

Federal da Bahia

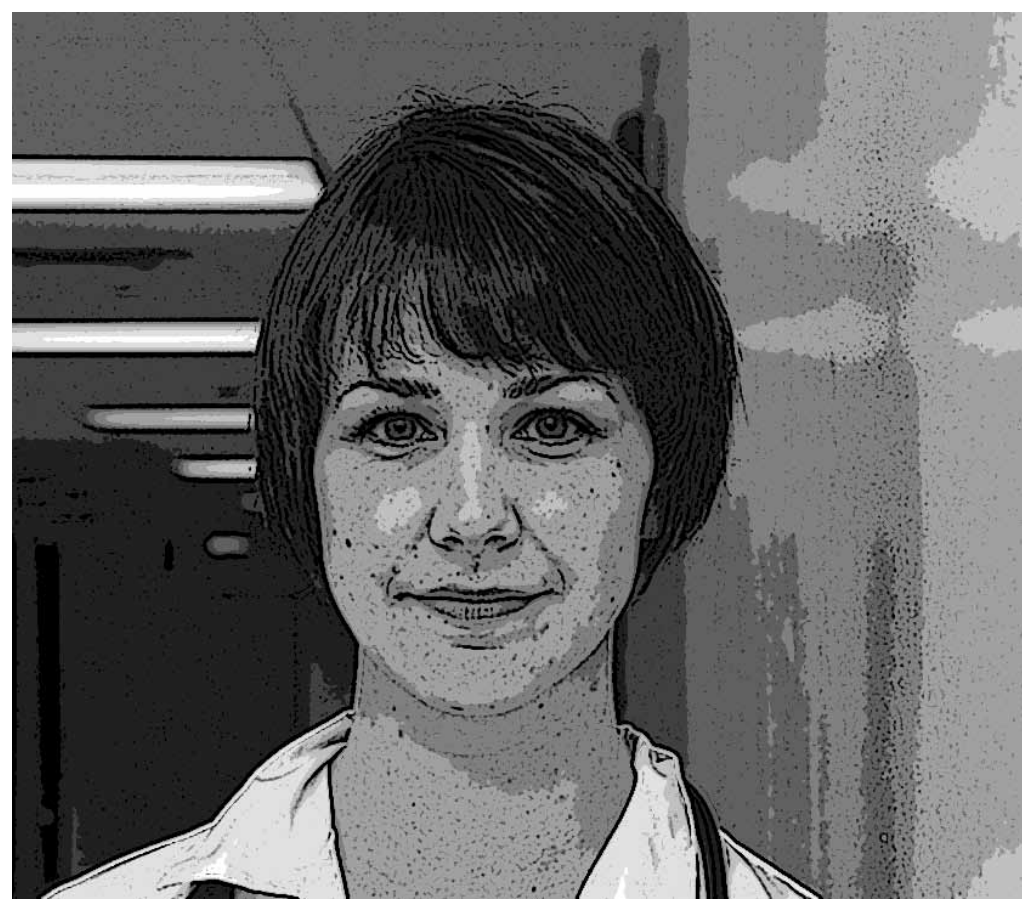


Resumo: Este artigo tem como objetivo discutir a formação de psicólogos na modalidade de residência multiprofissional, considerando os significados e os sentidos construídos pelos residentes e preceptores sobre o cotidiano da aprendizagem pelo trabalho. Trata-se da primeira turma de uma residência multiprofissional em saúde coletiva com área de concentração em saúde mental, iniciada em 2008, com 15 residentes de seis áreas diferentes, três delas psicólogas. Inspirou-se teórico-metodologicamente na vertente da Psicologia social das práticas discursivas e da produção de sentido e na escrita etnográfica da Antropologia interpretativa. Utilizaram-se, na coleta de dados, entrevistas semiestruturadas com os residentes, grupo focal com os tutores e diário de campo. A análise dos repertórios interpretativos das psicólogas-residentes e demais entrevistados está organizada em dois eixos: Psicologia como campo de saber e como campo de fazer. A participação das psicólogas na residência multiprofissional tende a refinar as habilidades do seu núcleo profissional compatíveis com as necessidades do campo da saúde mental. Essa residência tende a proporcionar uma formação transdisciplinar, uma vez que está atenta à dimensão subjetiva da formação dos residentes.

Palavras-chave: Residência não-médica. Formação do psicólogo. Saúde mental. Transdisciplinaridade.

\begin{abstract}
The objective of this study is to discuss the education of psychologists within multi-professional residencies, considering the meanings and the sense constructed by the residents and tutors about the daily learning process during work. The focus of the study is the first group of residents in a multi-professional residency in collective health with emphasis in mental health. The residency started in 2008 with 15 residents from six different areas, three of them from psychology. The study's theoretical-methodological base was inspired by a line of the social psychology of discursive practices and meaning production, and on the ethnographic writings from interpretative anthropology. For data gathering, the study used semistructured interviews with the residents, a focus group with the tutors, as well as a field diary. The analysis of the interpretative repertoires of the psychology residents and other interviewees was organized into two main areas: psychology as an area of knowledge and as an area of construction. The participation of the psychologists in the multi-professional residency tends to refine the abilities of their professional body congruent with the needs of the field of mental health. This residency is inclined to provide a transdisciplinary education, once it is attentive to the subjective dimension of the education of the residents.
\end{abstract}

Keywords: Non-medical residency. Psychologist education. Mental health. Transdisciplinarity.

Resumen: Este artículo tiene como objetivo discutir la formación de psicólogos en la modalidad de residencia Multiprofesional, considerando los significados y sentidos construidos por los residentes y preceptores sobre el cotidiano del aprendizaje por el trabajo. Se trata del primer grupo de una residencia Multiprofesional en salud colectiva con área de concentración en salud mental, iniciada en 2008, con 15 residentes de seis áreas diferentes, tres de ellas psicólogas. Se inspiró teórico-metodológicamente en la vertiente de la psicología social de las prácticas discursivas y producción de sentido y en la escrita etnográfica de la antropología interpretativa. Se utilizó en la colecta de datos entrevistas semiestructuradas con los residentes, grupo focal con los tutores y diario de campo. El análisis de los repertorios interpretativos de las psicólogas-residentes y demás entrevistados está organizada en dos ejes: psicología como campo de saber y campo de hacer. La participación de las psicólogas en la residencia Multiprofesional tiende a refinar las habilidades de su núcleo profesional compatibles con las necesidades del campo de la salud mental. Esta residencia tiende a proporcionar una formación transdisciplinaria, una vez que está atenta la dimensión subjetiva de la formación de los residentes.

Palabras claves: Residencia no-médica. Formación del psicológo. Salud mental. Transdisciplinariedad.

\begin{abstract}
O relatório desenvolvido pela III Conferência Nacional de Saúde Mental, de 2001, sustenta que a concretização dos princípios da reforma psiquiátrica passa pela implementação de políticas de desenvolvimento de recursos humanos na saúde. O relatório enfatiza a importância do exercício da ética profissional, a construção de um novo trabalhador, mais sensível às diferentes dimensões do cuidado em detrimento da valorização da especialização exacerbada comum aos processos hegemônicos de trabalho
\end{abstract}

em saúde. A residência multiprofissional pode ser a modalidade de especialização que favoreça o desenvolvimento de novos profissionais. No Brasil, residências não médicas multiprofissionais em saúde existem desde o ano 1978 (Brasil, 2006) e embora, como uma das estratégias de qualificação de profissionais de saúde, elas tenham sido regulamentadas pela Lei $\mathrm{n}^{\circ} 11.129$, de 30 de junho de 2005, percebemos a escassez de estudos sistemáticos que contribuam para a compreensão das residências não médicas 
a fim de consolidar as políticas de reordenação de formação de recursos humanos para a área da saúde, particularmente no campo da saúde mental. Há estudos que não focalizam a saúde mental diretamente, mas que analisam as contradições e os conflitos inerentes ao processo de institucionalização da residência multiprofissional e apontam que tal modalidade de especialização pode contribuir com a construção das mudanças necessárias na produção de serviços de saúde que têm potencial para fomentar a integralidade da saúde a partir da articulação serviço e espaços acadêmicos. Além disso, residência multiprofissional pode favorecer a reorganização do processo de trabalho em saúde, constituindo um incentivo concreto para o trabalho coletivo, com tendência mais interdisciplinar e intersetorial (Dallegrave \& Kruse, 2009; Clemente, Mattos, Grejanin, Santos, Quevedo, \& Massa, 2008; Simoni, 2007).

No caso da participação de psicólogos no SUS, segundo Boing e Crepaldi (2010), a partir de 2004, há portarias ministeriais que incentivam o apoio matricial de apoio à saúde da família, o que reforça essa ampliação. Apesar disso, os referidos autores apresentam um panorama ainda frágil no que diz respeito à garantia normativa de inserção dos psicólogos no SUS. Entre os 964 documentos oficiais analisados relativos à regulamentação e à implantação de políticas públicas no Brasil, apenas 14 deles se referem à inclusão do profissional de Psicologia, predominantemente com participação nos níveis secundário e terciário de assistência à saúde.

Yamamoto, Souza, Silva e Zanelli (2010) afirmam que a principal modalidade de pós-graduação utilizada pelos psicólogos para se qualificarem é a especialização, seguida de mestrados e doutorados. 60,3\% dos psicólogos fizeram ou estavam fazendo uma especialização, apenas 19,4\% eram Mestres ou mestrandos e $5 \%$ deles Doutores ou doutorandos (Quadro 1). Não há dados que situem o vínculo dos psicólogos em residências por área profissional ou nas multiprofissionais.

Quadro 1. Distribuição de psicólogos por modalidades e pós-graduação

\begin{tabular}{llll}
\hline Modalidades de pós-graduação & Especialização & Mestrado & Doutorado \\
\hline Percentuais & $60,3 \%$ & $19,4 \%$ & $5 \%$ \\
\hline
\end{tabular}

É interessante ressaltar que, no caso da modalidade especialização, 76,3\% dos psicólogos estavam vinculados a especializações em Psicologia, e apenas 23,7\% a outro campo de conhecimento; no caso do mestrado, 66,3\% em Psicologia e 33,7\% em outro campo de conhecimento, e a mesma tendência apresenta-se no doutorado, com 70,7\% em Psicologia e 29,3\% em campos afins (Quadro 2).

Quadro 2. Distribuição de psicólogos por modalidades de pós-graduação por área de concentração

\begin{tabular}{|c|c|c|c|c|c|}
\hline $\begin{array}{l}\text { Modalidades de } \\
\text { pós-graduação }\end{array}$ & Especialização & Mestrado & & \multicolumn{2}{|c|}{ Doutorado } \\
\hline $\begin{array}{l}\text { Área de } \\
\text { concentração da } \\
\text { pós-graduação }\end{array}$ & Psicologia Áreas afins & Psicologia & Áreas afins & Psicolo & Áreas afins \\
\hline$\%$ & 23,7 & 66,3 & 33,7 & 70,7 & 29,3 \\
\hline
\end{tabular}


Almeida-Filho (1997, p. 17) propõe uma noção de transdisciplinaridade "baseada na possibilidade de comunicação não entre campos disciplinares, mas entre agentes em cada campo, através da circulação não dos discursos (pela via da tradução), mas pelo trânsito dos sujeitos dos discursos".
A constatação da existência significativa de busca de psicólogos em pós-graduação em campos afins possibilitou a tais pesquisadores questionar se isso ocorre pela escassez de oferta de oportunidade de formação dentro da área profissional (Psicologia) ou se refere a uma necessidade percebida pelos psicólogos em campos afins para aperfeiçoar o desempenho profissional e abrir novas possibilidades de trabalho. Segundo eles, essa questão está em aberto, e necessita de mais pesquisas.

A atuação protegida dos psicólogos (porque nos moldes do consultório particular e como profissional liberal), consequência da maior ênfase desse modelo na graduação, tem dificultado a construção de novos processos de trabalho que se impuseram com o aumento da participação da categoria nos serviços públicos de saúde, nos vários níveis de assistência à saúde (Spink, 2003; Lima, 2005; Carvalho, Bosi \& Freire, 2009). Nesse sentido, aceitar a condição de estar trabalhador do SUS significa um progressivo distanciamento do modelo de profissional liberal e autônomo para uma atuação que responda à relação entre a questão social e as políticas públicas (Yamamoto, 2003).

No que se refere à inserção dos psicólogos em equipes de trabalho (uni ou multiprofissionais), Martins e Puente-Palacios (2010) concluem que eles estão satisfeitos com o trabalho, apresentam crenças positivas, percebem nas equipes poucos conflitos, apesar de serem mal renumerados, de serem muito exigidos no trabalho e de terem que se dedicar muito ao próprio desenvolvimento profissional. Os autores destacam ainda que os psicólogos inseridos em equipes multiprofissionais desenvolvem quantidade maior e mais diversa de atividades do que aqueles que estão nas equipes uniprofissionais, tendência que tem exigido mais habilidades e competências.
Neste artigo, apresentamos reflexões sobre a formação em serviço a partir do acompanhamento de uma residência multiprofissional com o objetivo de contribuir com a discussão sobre as articulações entre campo de conhecimento e núcleo profissional. A noção de núcleo constitui um instrumento teórico utilizado para especificar a demarcação de uma área definida de saberes e práticas, identidades profissionais e disciplinares. O campo seria caracterizado por um espaço de fronteiras indefinidas, onde vários núcleos procurariam auxílio para lidar com questões teóricas e práticas (Campos, 2000).

Almeida-Filho (1997, p. 17) propõe uma noção de transdisciplinaridade "baseada na possibilidade de comunicação não entre campos disciplinares, mas entre agentes em cada campo, através da circulação não dos discursos (pela via da tradução), mas pelo trânsito dos sujeitos dos discursos". Essa noção de transdisciplinaridade é alicerçada pelo paradigma da elucidação, na busca de integração totalizadora, correspondendo à noção de "ciência que se configura cada vez mais como uma prática de construção de modelos, de formulação e solução de problemas num mundo em constante mutação" (Almeida-Filho, 1997 p. 08). Nessa direção, a loucura, o louco e seu entorno configuram-se como objetos complexos no campo da saúde mental, que não prescindem de especialistas, mas que exigem cada vez mais operadores transdiciplinares da ciência, ou seja, aqueles que lidam com um objeto "multifacetado, alvo de diversas miradas, fonte de múltiplos discursos, extravasando os recortes disciplinares da ciência" (Almeida-Filho, 1997, p.11). Nesse particular, a análise das dinâmicas cotidianas da produção de conhecimento, seja em grupos multidisciplinares de pesquisas, seja em equipes de trabalho, deve contar com os tais operadores, que seriam aqueles que transitam durante a sua formação e 
experiência de trabalho em áreas diversas de conhecimento, desenvolvendo uma sensibilidade privilegiada para a articulação de saberes e para o manejo da complexidade dos fenômenos (objetos complexos), não sendo prevista, necessariamente, a mudança dos campos de conhecimento, e sim, maiores possibilidades de compreensão dos objetos complexos (Almeida-Filho, 1997). Os objetos complexos são "aqueles que não se subordinam a nenhuma aproximação meramente explicativa, e que nem por isso mereceriam ser excluídos do campo de visão da ciência justamente por serem... indisciplinados" (Almeida-Filho, 1997, p. 10). Tal noção de transdisciplinaridade desloca o foco de reflexão dos campos de conhecimento (típico de algumas versões teóricas que buscam conceituar interdisciplinaridade) para os representantes dos campos (diferentes núcleos profissionais). No entanto, nem todos os representantes de campo de conhecimento desejam ou têm pretensão de se tornarem tais operadores, sequer essa seria uma vantagem por si só, embora o autor ressalte a necessidade de aumentarmos a presença dos tais operadores transdisciplinares da ciência.

No conceito da pedagogia da implicação, encontramos outra fonte para problematizar a formação de profissionais de saúde complementar as noções de núcleo/campo e transdisciplinaridade. Com essa noção, Fagundes (2006, p. 217) ressalta que, para haver transformação dos sujeitos, são necessárias experiências cotidianas de trabalho que promovam a "gestão de processos de mudança de si e dos entornos, mudanças direcionadas para a construção de saberes, de práticas e do poder de autoria, de modo coletivo e produtor de subjetivação". A pedagogia da implicação "propicia processos coletivos de auto-análise e auto-gestão e ativa a capacidade criativa e de intervenção nas situações vivenciadas pelos participantes (...) educação dirigida a e produzida por coletivos de trabalho e de militância" (que têm por finalidade a "afirmação da vida") (Fagundes, 2006, p. 218).

\section{Métodos de coleta e análise dos dados: sujeitos, contexto da pesquisa e inspiração teórico-metodológica}

Este artigo é um dos resultados da pesquisa intitulada Ensino em Serviço e Cuidado em Saúde Mental: um Estudo Etnográfico sobre uma Residência Multiprofissional, realizada na Bahia e financiada pela Fundação de Apoio à Pesquisa da Bahia (FAPESB), entre 2008 a 2009. Trata-se de uma pesquisa qualitativa com inspiração etnográfica, e o contexto do estudo foi a primeira turma de uma residência multiprofissional em saúde coletiva com área de concentração em saúde mental, iniciada em 2008, com 15 residentes (3 enfermeiros, 3 terapeutas ocupacionais, 3 psicólogos e 2 assistentes sociais). Cada equipe era composta por 3 ou 4 residentes de diferentes categorias, que permaneceram nessa subdivisão durante os dois anos da residência. Os grupos multiprofissionais da residência desenvolviam ações em quatro diferentes cenários de prática-aprendizagem da rede pública de saúde mental de Salvador, a saber: 2 Centros de Atenção Psicossocial de Saúde MentalCAPS II, 1 CAPSad e 1 CAPSi. Cabe ressaltar que, inicialmente, um hospital psiquiátrico de médio porte fazia parte dos cenários de prática-aprendizagem, mas foi substituído por mais um CAPS II, por ter sido considerada inviável a implantação dessa proposta desinstitucionalizante no hospital. O rodízio proporciona aos residentes a oportunidade de atuar com diferentes públicos-alvo e modelos substitutivos e de realizar atividades distribuídas em 60 horas semanais $(80 \%$ delas práticas e $20 \%$ em aulas teóricas e encontros com a tutoria). Os residentes eram acompanhados individualmente por tutores dos seus respectivos núcleos profissionais e, institucionalmente, nos cenários de prática- 
aprendizagem, por preceptores, profissionais dos serviços de saúde mental.

Aplicamos um questionário profissiográfico com o intuito de identificar objetivamente as características acadêmico-profissionais de todos os residentes, focalizando as experiências anteriores com a saúde mental, dados sociodemográficos e acadêmicos. Esse levantamento foi útil para desenvolver o roteiro de entrevista, proporcionando pontos de partida mais específicos para a realização das entrevistas individuais. Realizamos entrevistas semiestruturadas individuais com os 15 residentes, solicitando o relato das atividades realizadas nos cenários de prática-aprendizagem com detalhamento dos casos concretos acompanhados, bem como as estratégias pedagógicas utilizadas na residência (tutoria e aulas teóricas).

Com a finalidade de obter maior aprofundamento e contextualização das experiências relatadas, e não sendo operacional o acompanhamento das quatro equipes, pois tínhamos um grupo pequeno de pesquisadores, apenas uma delas foi acompanhada em um CAPS II em suas atividades externas e internas ao serviço, através de observação participante, com elaboração de diários de campo. Por fim, fizemos uma entrevista com a coordenação do programa e um grupo focal com todos os seis tutores da residência. Todos os sujeitos contactados consentiram em participar das entrevistas, que foram gravadas e transcritas na integra. A análise do material coletado - que se desenvolveu por meio de leitura exaustiva das entrevistas e socialização dos diários de campo em discussão no grupo de pesquisa - permitiu a identificação dos repertórios interpretativos dos residentes e dos tutores. Por estarmos muito interessados na formação dos psicólogos, neste artigo, focalizamos principalmente os repertórios interpretativos das três psicólogas, e, para cumprir o objetivo de compreender os significados e sentidos construídos em torno da Psicologia como campo de saber e campo de fazer, identificamos, no corpus textual das demais entrevistas e diários de campo, indicadores narrativos que esclarecessem como essa construção acontecia nos subcontextos de formação de tais profissionais.

Esta pesquisa tem como inspiração teóricometodológica a vertente da Psicologia social das práticas discursivas e produção de sentido (Spink \& Medrado, 2000) e a escrita etnográfica da Antropologia interpretativa (Geertz, 1989). Essas abordagens convergem no sentido de valorizar a construção social dos sentidos cotidianos e de considerar as narrativas dos sujeitos potenciais para a compreensão da realidade estudada. $\mathrm{Na}$ análise dos dados, consideramos que as ações produzidas nos espaços cotidianos dos cenários de prática-aprendizagem podem ser analisadas como esforços continuados de produção de sentido em processos ativos e interativos: produção de sentido que retoma conhecimentos do imaginário social e formativo que produz reinterpretações à luz das situações concretas vivenciadas no aqui-agora.

Adotamos técnicas sensíveis ao registro dos repertórios interpretativos, ou seja, "conjunto de termos, descrições, lugarescomuns e figuras de linguagem" (Spink \& Medrado, 2000, p. 47) que ocorreriam nos cenários de prática-aprendizagem nas interações dos sujeitos da pesquisa ou no rememorar dessas relações. Os sentidos que algum evento assume no cotidiano dos residentes acompanhados foram buscados "através da não-regularidade e da polissemia (diversidade) das práticas discursivas" (Spink \& Medrado, 2000, p. 44). Essa perspectiva envolve, em sua análise, as "maneiras a partir das quais as pessoas produzem sentidos e se posicionam em relações cotidianas" (Spink, 2000, p. 45). 
Inscrever a ação (fixação do significado em alguma forma de registro) possibilita a passagem da mera descrição dos fatos e modelos explicativos nativos para a elaboração de uma interpretação do pesquisador (Geertz, 1989). Tal descrição etnográfica é interpretativa e microscópica. O que se interpreta é a fluidez do discurso social, buscando salvar o dito, evitando assim a sua extinção e fixando-o em formas pesquisáveis. O sentido atribuído à característica microscópica da descrição autoriza a ressalva de que "interpretações mais amplas e análises mais abstratas" surgem de "um conhecimento muito extensivo de assuntos extremamente pequenos" (Geertz, 1989, p. 31). Este estudo foi submetido e aprovado pelo Comitê de Ética em Pesquisa vinculado à Pós-Graduação em Psicologia do Instituto de Psicologia (IPS/UFBA), garantindo aos participantes o direito de conhecer os procedimentos de coleta e análise de dados, além de anonimato e sigilo.

\section{Resultados e discussões}

\section{Psicologia como campo de saber: pluralismo e hierarquização dos saberes}

As três residentes-psicólogas participantes da residência multiprofissional em saúde mental estudada possuem experiências anteriores ao seu ingresso na residência bastante variadas, no sentido de cada uma possuir vivências e ênfases de graduação ou em áreas diversas do tripé acadêmico de pesquisa-ensinoextensão. Em suas experiências acadêmicas anteriores, cada psicóloga-residente privilegiou um determinado eixo desse tripé com que mais se identificava. Elas podem ser consideradas recém-formadas, uma vez que todas apresentam menos de cinco anos de graduadas, sendo que uma residente (R1) passou da graduação diretamente para a residência estudada, outra residente (R4) estava vinculada a uma residência por área profissional em Psicologia, mas, com a aprovação na residência multiprofissional, optou pela saída e ingresso na residência estudada, e a terceira residente (R5), depois da graduação, trabalhou durante dois anos em um equipamento da assistência social antes de ingressar na residência multiprofissional. Tais experiências remetem às dimensões complementares da formação na graduação e da inserção profissional em determinados contextos de trabalho, participação em grupo de pesquisa, atividade de extensão, atividades práticas de disciplinas cursadas na graduação e estágio curricular no programa de intensificação de cuidado de psicóticos. Percebemos que a aproximação anterior concreta e reflexiva das residentes com realidades sociais de pessoas em sofrimento mental, seja em contextos de intervenção (práticas ou atividades de extensão), seja de pesquisa, despertaram a importância de considerarem diferentes olhares e contribuições da Psicologia e de áreas afins para o cuidado em saúde mental.

As atividades desenvolvidas por todos os 15 residentes eram sempre realizadas dentro e fora dos serviços substitutivos, exceto quando no rodízio os residentes estiveram no hospital psiquiátrico, realizando apenas tarefas internas. Esse foi um dos motivos porque a proposta da residência se tornou incompatível com a dinâmica do hospital. O formato e os objetivos das atividades realizadas dependiam do tipo de CAPS (II, ad ou ia) e, especialmente, da clientela-alvo (crianças e adultos com transtornos mentais e/ou com dependência química de álcool e outras drogas). Atividades tais como: atendimentos individuais, visitas domiciliares e institucionais, acompanhamento de crianças no espaço de convivência, de adultos nas residências terapêuticas, grupos e uma diversidade de oficinas (geração de renda e de desenho, vide bula, cultura e lazer, espaço coletivo, etc.) e assembléias, etc. Todos os residentes planejavam, executavam 
e avaliavam suas atividades em dupla (uma das equipes em trio) com outro residente, com profissionais dos cenários de práticas e tutores. Apesar de estarem em grupos de quatro trabalhadores-aprendizes por unidade, organizavam o processo de trabalho, muitas vezes, em dupla, exceto em atendimentos individuais. Cabe ressaltar que uma das equipes contava com três residentes, uma vez que eram em número total de 15 . A experiência de aprendizagem pelo trabalho, proporcionada pela participação em uma residência multiprofissional, é percebida pelos residentes como capaz de construir um questionamento constante de suas práticas (individuais e coletivas), resultando em um cuidado mais qualificado e resolutivo em relação aos problemas apresentados pelos usuários atendidos. Em relação a isso, destacamos abaixo a narrativa de uma das residentes-psicólogas, que teve a experiência singular de fazer parte de uma residência por área profissional (Psicologia clínica, da qual se desligou, antes de finalizá-la, para ingressar na atual residência multiprofissional):

Era só em psicologia (residência por área profissional), e, além disso, a residência de lá tinha uma abordagem bem psicanalítica, né?! E o enfoque mais ambulatorial, assim, a gente ficava na, diversos setores do hospital. (...) Então, é totalmente diferente, assim, a abordagem, o enfoque, e todas as disciplinas eram voltadas mesmo pra psicanálise, né?! (R4/psi., comunicação pessoal (CP), 05/02/09)

De acordo com o exposto sobre sua preferência pela residência multiprofissional e desistência pela residência por área profissional, a residente-psicóloga destaca as limitações do cuidado de pessoas em sofrimento mental em sistema ambulatorial ou de internação no hospital psiquiátrico, os efeitos pouco resolutivos daí decorrentes, além de criticar o excessivo enfoque psicanalítico em detrimento de contribuições de outras abordagens teórico-práticas.
Percebemos, nas narrativas dos demais residentes, a negatividade atribuída à restrição e/ou hierarquização em uma única abordagem teórica, seja da Psicologia, seja de outro campo de conhecimento. Frequentemente, quando questionadas sobre o cotidiano de aprendizagem nos cenários de prática e sobre as estratégias de intervenção utilizadas em situações concretas, as entrevistadas reafirmam a complementaridade de diferentes abordagens teórico-metodológicas: "A moeda prata é a Psicologia, né? Lá no serviço, tendencialmente, a psicanálise, porque 'a estrutura, e o vínculo, e a transferência', aquele dicionário todo que a gente tem que aprender lá, né? É o que norteia a clínica" (R2/enf., CP, 30/03/09).

(...) Mas agora, nos CAPS, eu percebo que a psiquiatria não está tão forte assim, mas existe a Psicologia, o psiquê, na verdade, que é algo muito forte (R10/ass., CP, 07/04/09).

\begin{abstract}
Aí eu falei que a gente deveria propor outras discussões, e que a R3/Edf tem favorecido muito essa discussão de corpo fora dessa perspectiva psicologizante do corpo. E quando eu falei isso, a R5/Psi na mesma hora foi defender a Psicologia, ela foi falar: 'não, porque eu não acho que a gente tem que negar, a gente tem que acrescentar, a gente não sei o quê'. Aí na hora, eu falei: 'não, eu não estou negando que a gente deva deixar de entender a parte da Psicologia, mas, assim, o entendimento a partir da Psicologia já é uma coisa instituída, muitas discussões vêm desse lugar, não acho que a gente tem que negar, mas a gente pode acrescentar (R14/ to, CP, 23/04/09)
\end{abstract}

Existe uma forte influência da psicanálise não só na residência mas também no campo da saúde mental como um todo, onde existem serviços substitutivos referenciados pela psicanálise e uma literatura expressiva da relação dessa área com a saúde mental. Tal preponderância acabou por causar um desconforto entre parte dos residentes, tanto pela novidade do discurso psicanalítico e por considerarem sua linguagem hermética 
como pelo excesso de teorização. No entanto, a partir do momento em que o discurso psicanalítico fazia sentido para a prática concreta, por exemplo, na clínica do autismo, havia produção de sentido positivo por parte das diversas categorias profissionais, inclusive da Psicologia, embora a premissa fosse a de que uma vertente teórico-prática não ocupasse a posição totalizadora no que diz respeito à clínica em saúde mental, que se pretendia ampliada:

Eu mesmo não gostava muito de psicanálise, mas depois que eu fiquei no CAPS infantil com o caso de uma criança autista, eu fiz: 'psicanálise, não tem pra onde correr'. (...) Então, assim, aquilo que eu leio, quando eu estou com o usuário, começa a fazer sentido, e isso é maravilhoso, (...) é coisa mesmo da residência que permite isso (R5/ psi., CP, 19/05/09)

A percepção de existente tendência à hierarquia do saber psicológico na residência foi acompanhada de um movimento para a suplantação dessa problemática, sendo palco de discussões nos diversos momentos de tutoria. A Psicologia e o saber psicanalítico foram vistos como equivalentes entre os residentes não psicólogos, e a hegemonia da compreensão dos usuários -acompanhados em sua dimensão subjetiva (embasada pela psicanálise) - constituiu um dos tensionamentos dentro da residência. $\mathrm{O}$ tensionamento causado pela hierarquização de um dos saberes existentes no campo da saúde mental e o desdobramento da sua contenção remete à tendência de superar a noção de interdisciplinaridade auxiliar em direção a uma perspectiva transdisciplinar na residência (Almeida-Filho, 1997). A interdisciplinaridade auxiliar é definida como aquela que:

auxilia a interação de diferentes disciplinas científicas ( $A, B, C$ e $D)$, sob a dominação de uma delas (no caso $D$ ), que se impõe às outras como campo integrador e coordenador. (...) "Dentro de um quadro de relações de poder muito desiguais entre as diversas corporações e disciplinas, muitas das práticas usuais de colaboração entre profissionais (...) acabam sendo auxiliares" (Vasconcelos, 1996 citado por Almeida-Filho, 1997, p. 12)

Esse é um ponto fundamental para sinalizar a capacidade de uma residência multiprofissional funcionar como um espaço de produção de operadores da ciência (Almeida-Filho, 1997). Deve-se estar vigilante para a hierarquização entre os campos de conhecimento de modo que um deles não tome um lugar de maior poder em relação aos demais, diminuindo a potencialidade de essa estratégia educativa gerar processos transdisciplinares de formação e de trabalho. $\mathrm{Na}$ ausência de um discurso psiquiátrico, inclusive pela inexistência de um residentemédico (por conseguinte, de um tutorpsiquiatra) em modalidades de residência não médicas, a Psicologia e os seus representantes deverão resistir à tentação de não assumir a hegemonia do campo, ao menos sem medir as consequências negativas para o avanço do campo da saúde mental.

A produção de sentido das residentespsicólogas sobre o rodízio entre os CAPS se dá a partir de dois pontos de vista. Um deles diz respeito ao impacto da saída da equipe de residentes a cada seis meses do cotidiano do usuário e o outro, às oportunidades decorrentes do trânsito entre os serviços para a formação do próprio residente. Para elas, o rodízio proporciona "diversidade e riqueza", porque permite aproximação com modalidades de tratamentos diferentes, lidar com equipes diversas, com as especificidades institucionais de cada CAPS e com as diferenças do cuidado para cada um dos públicos-alvo. Por outro lado, elas ponderam que a entrada e a saída de equipes de residentes nos cenários de prática têm a desvantagem de romper precocemente o vínculo com os usuários acompanhados pela respectiva equipe de residentes (ou mesmo da dupla), além de poder ocasionar 
a descontinuidade dos projetos desenvolvidos durante a permanência dessa equipe nos serviços. Para minimizar esse problema, ao final de cada passagem das equipes pelo serviço, há o momento de apresentação dos relatórios das experiências no campo, quando são apresentados todas as atividades desenvolvidas ao longo do semestre, os avanços, as dificuldades e os insucessos. Esse é caracterizado como um momento de passagem (entregar/confiar) do serviço à outra equipe que deverá, a partir dos pontos positivos ressaltados, tentar dar continuidade às intervenções e aos projetos desenvolvidos.

\section{Psicologia como campo de fazer: escuta, negociação e setting-território}

Diferentemente dos demais residentes, podemos perceber a existência de uma especificidade muito sutil no trabalho das psicólogas, no sentido de enfatizar a dimensão subjetiva em relação ao processo saúde-doença-cuidado do usuário. A formação prévia em Psicologia permite a essas residentes a obtenção de uma escuta qualificada que orienta a tomada de decisões tendo como foco as necessidades do usuário:

Tem um paciente mesmo que eu tô acompanhando assim mais de perto, com (R7/enf.), assim, e aí eu acabo não vendo assim muita diferença no trabalho, eu acho que é muito mais uma questão do olhar assim, do que o que você vai enfatizar (R4) psi., CP, 05/02/09)

Não havendo tanta diferença entre os fazeres dos demais profissionais para os fazeres desenvolvidos pelas psicólogas, o desafio é conseguir aprimorar essa habilidade de escutar - que, para essa categoria profissional, poderia ser considerada inicialmente uma tecnologia leve-dura (Merhy, 1999) - no território. Segundo Lima (2006), a escuta é a ferramenta terapêutica que melhor caracteriza o trabalho do psicólogo nas Unidades Básicas de Saúde - UBS e ambulatório de saúde mental, em Salvador:

À escuta é atribuído um caráter mais refinado, uma certa curiosidade desvelada em um estado de permanente atenção requintada por parte do profissional. Essa competência está associada à ação básica do seu trabalho, caracterizada pela habilidade do psicólogo de manter-se alerta, ter interesse sobre a fala significativa, que remonta à história dos sujeitos, revelada a partir de seus sentimentos, emoções, desejos, conflitos (Lima, 2006, p. 299)

Lima ressalta que a reivindicação legítima dos profissionais de Psicologia em relação à importância do seu trabalho e do cuidado dos problemas de saúde a partir do manejo da subjetividade, portanto, da escuta, não ocorre sem tropeços e obstáculos no que diz respeito aos desafios e dificuldades encontradas no oferecimento de atendimentos psicológicos nos serviços públicos de saúde. No referido estudo, Lima categorizou a escuta psicológica como cautelosa ou asséptica, dependendo da capacidade de inclusão e manejo dos psicólogos em relação às dimensões individual e coletiva de significação dos problemas apresentados pelos usuários.

Merhy (1999, pp. 307-308) é um dos autores que tem se preocupado com a discussão sobre tecnologias em saúde, destacando o lugar das tecnologias leves ou relacionais para a produção de saúde. Ele as classifica em tecnologias duras (aparelhos e ferramentas de trabalho), em tecnologias leves-duras (saberfazer bem estruturado, bem organizado, bem protocolado, normalizável e normalizado) e em leves (baseadas nas relações de vínculo e aceitação). Enfatizar a tecnologia leve (Merhy, 1999), que é um tipo de tecnologia que todos os profissionais de saúde devem utilizar, demarca um desafio para a triangulação que se tenta apontar neste estudo sobre núcleo, campo e transdiciplinaridade. 
Então, eu acho que é esse o diferente que se faz, então, não é o setting, eu acho que uma das contribuições que tem me dado muito é isso, não é o setting clássico da aplicação para uma intervenção, mas sim, a nossa presença. Cada vez mais, é a nossa presença aqui que faz com que tenham infinitas possibilidades pra gente fazer as intervenções nos usuários. E é muito mais rico e, também, às vezes, é mais complexo (R5/psi., CP, 19/05/09).

Em relação ao núcleo profissional da Psicologia, percebemos, exemplificado pela habilidade da escuta, que o fundamental é refiná-la, particularmente apostando no seu efeito em cenários de cuidado menos clássicos. Construir o setting no território, cultivar o cuidado no terreno do usuário é um dos aprendizados mais ricos que a residência parece fornecer às psicólogas, informações que auxiliam no diagnóstico por proporcionar o compartilhamento de situações concretas que fortalecem o vínculo e facilitam as intervenções com os mesmos e com sua rede social. Com o uso da noção de território/territorialidade, buscamos considerar, ao menos, três sentidos: primeiro, como "espaço-suporte, que delimita a área de atuação de uma equipe, um serviço, um programa, cumprindo a missão de materializar uma acolhida, um vínculo", e, segundo, como "espaço-humano", mais subjetivo e fenomenológico, "com todas as suas expansões de referência, signos e significados (...), rede de iniciativas múltiplas que agenciam cuidados e inclusão social" (Pitta, 2001, p. 278), além de espaço sociopolítico de exercício de cidadania e de afirmação identitária (Lima, Jucá \& Nunes, 2010). Tais contribuições, que vêm do campo da saúde mental, mais do que do núcleo profissional da Psicologia, potencializam uma habilidade do seu núcleo, ou seja, a escuta da dimensão subjetiva do sofrimento em settings não clássicos/territoriais.

A importância de tais experiências concretas de cuidado no território aparece quando o residente busca desconstruir o preconceito/ estigma atribuído aos usuários devido a sua condição de pessoa com transtorno mental, a partir da conversa e da negociação do gerenciamento da vida do usuário com vizinhos e familiares. Para desfrutar dessa potencialidade, de acordo com os entrevistados, é preciso "estar disponível", "aberta", ou seja, "desconstruir o lugar de psicólogo", "ter vontade de contribuir", "desenvolver gosto" pela saúde mental. Dessa forma, constata-se que a "relação protegida" (Spink, 2003) em Psicologia voltada para a saúde mental, tão fortemente presente na graduação, atendendo pessoas em sofrimento psíquico dentro de settings clássicos e com parâmetros de profissão liberal, restrita somente a um referencial teóricometodologico, é fortemente questionada e revisada pelas psicólogas-residentes. Pode-se dizer que tais profissionais em formação, por causa de questões concretas enfrentadas na residência, são convocados a produzir novas tecnologias de cuidado e modos de trabalhar em saúde mental que muitas vezes não foram enfatizados durante o processo de formação protegida e uniprofissional:

Não tem, na verdade, de saúde mental mesmo, a gente não, eu pelo menos não vi quase nada assim (referência à graduação), (...) porque a forma como é feita, pelo menos na minha época, (...) de você tá indo a hospital psiquiátrico, primeiro que era em hospital psiquiátrico, eu acho que, dentro dessa nova realidade, o mínimo que poderia ser feito é que fossem nos CAPS, né? Porque são as novas formas de tratamento no modelo substitutivo, (...) a forma que era feito também, você ir fazer entrevista com paciente, anamnese (...), eu me sentia assim num zoológico (R4/psi., CP, 05/02/09)

O desenvolvimento de tais habilidades tende a aumentar o "poder contratual" de cada sujeito/usuário, uma vez que, "no universo social, as relações de troca são realizadas a partir de um valor previamente atribuído para cada um indivíduo dentro do campo social, como pré-condição para qualquer processo 
de intercâmbio" (Tykanori, 2001, p. 55), e, no caso das pessoas com transtorno mental, essa capacidade está diminuída, as vezes, totalmente anulada.

As práticas realizadas são percebidas, pelas próprias residentes, como mais resolutivas. Um aspecto muito ressaltado pelas entrevistadas é que elas têm adquirido uma capacidade de negociação para lidar com a hierarquia, sutil ou estarrecedora, apresentada por alguns profissionais e tolerância e diálogo em situações conflitivas, pouco imaginadas anteriormente, como habilidades tão significativas para a sua atuação. Para renovar o cuidado em saúde mental, ou seja, para suplantar a cristalização dos papéis profissionais, é necessário vencer o preconceito tecnológico, aquele que enfatiza uma certa maneira de se realizar as práticas que cada profissional adota a partir de um repertório comportamental modelado por sua profissão, sem se preocupar com o sujeito que está sob os seus cuidados, muitas vezes blindado em um não tratar tudo o que se fizer fora desse repertório (Goldberg, 2001).

Essas habilidades de negociar e de estabelecer acordos que se orientam para a atenção integral aos usuários encontram-se bastante presentes nos repertórios interpretativos das psicólogas-residentes. Elas são utilizadas em momentos variados e se referem a diferentes participantes do cuidado em saúde mental. Com o usuário, tal modo de proceder se desenvolve com o intuito de fazê-lo refletir sobre suas ações dentro e fora dos serviços, sobre suas atividades e questões cotidianas, possuindo um objetivo terapêutico que se relaciona com a investigação e a intervenção nos determinantes do sofrimento psíquico:

(...) Eu não quero que ele me obedeça (referese a uma criança autista), eu quero que a gente negocie, por exemplo, se ele pega os óculos de uma pessoa, aí vem os profissionais daqui que criticavam a minha postura e de outros profissionais e falam: 'devolva agora'! (...) Então, negociava, contextualizava, conversava, inseria aquilo e, às vezes, de um ato de pegar os óculos, a gente entrava em coisas bem... Que eram realmente que tavam afetando ele (R1/psi., CP, 21/11/08)

Com os familiares dos usuários, tal habilidade de negociação é utilizada tendo em vista o estabelecimento de um cuidado conjunto, localizado principalmente fora dos serviços e em períodos em que as residentes não podem se fazer presentes, como à noite e nos fins de semana, momentos nos quais os serviços substitutivos não funcionam:

A gente foi procurar a família pra ver se família podia dar essa medicação, se o irmão podia dar, e aí a gente levou, aí o irmão disse que ia dar, e tal, aí depois que a gente voltou lá, ele disse: "olhe, ele chegou aqui jogando pedra em minha casa, pediu a medicação, eu peguei, dei toda de volta'. (...) Aí aquela coisa da gente tá sempre pensando e repensando... Daí fomos de novo tentar conversar, dialogar: 'não, não é assim, ele não tá bem, mas será que o senhor pode insistir um pouco mais?' (R4/psi., CP, 05/02/09)

Com os profissionais dos serviços e dos demais equipamentos da rede em geral de saúde mental, essa habilidade é vista como necessária no sentido de dar continuidade e de potencializar o cuidado do usuário através de pactos e de parcerias estabelecidas. Muitas vezes não se consegue exercer tal influência sobre os profissionais do serviço em questão, segundo as residentes-psicólogas, devido a, principalmente, três questões: a falta de tempo dos profissionais dos serviços, o investimento individual que cada técnico faz em um caso específico e a não concordância no modo de cuidado realizado pelo residente. Contudo, o incremento de maior número de profissionais nos casos constitui uma das principais estratégias das residentes-psicólogas para alcançar maior resolutividade no cuidado das pessoas que atendem. Elas procuram sensibilizar outros profissionais da rede e membros das comunidades dos usuários no sentido de corresponsabilizá-los pelo cuidado da 
pessoa em sofrimento mental. Para que isso ocorra, uma tática utilizada pelas residentespsicólogas é a exploração das representações sociais que acompanham a loucura e as profissões da área da saúde diretamente envolvidas em ações de cuidado em saúde mental, em benefício do usuário:

\begin{abstract}
(...) Tenho tido mais contato mais próximo com (assistente social de um ambulatório da rede) nesse campo do que com a técnica de referência do caso (profissional do CAPS), porque eu entendo que tem milhões de pessoas e tal, mas é uma coisa que... está conquistando mesmo as pessoas, pra que as pessoas possam estar próximas do caso, e, quanto mais pessoas a gente puder inserir, melhor, porque eu creio, assim, (...) que eu vou poder, que eu estou já inserida no trabalho e que eu vou potencializar ainda mais, é colocar outros membros no caso, de um técnico de plantão que estiver lá no CAPS circulando, que possa operacionar essa usuária e tal, outras pessoas também no caso de (suprimido o nome de uma usuária), pessoas que realizam cuidados com ela, que é a enfermeira e é assistente de enfermagem (R5/psi., 19/05/09)
\end{abstract}

Conhecer e acompanhar o trabalho das residentes-psicólogas sugere que lidar com pontos de vista diferentes e com orientações teóricas diversas dá sentido à multiprofissionalidade (ao campo), mais do que isso, com cada um dos representantes (residente, preceptor e tutor) de outros campos profissionais, reforça as especificidades do seu núcleo profissional e o reconhecimento de si mesmos como profissionais envolvidos subjetivamente em um novo processo de trabalho coletivo, que se pretende transdiciplinar. Esse pressuposto corrobora os trabalhos de Simoni (2007) e Ceccim (2005), que afirmam que o acesso a um campo de realizações interdisciplinares e multiprofissionais, em vez de produzir somente intersecções e intercruzamentos entre os diferentes saberes envolvidos em um determinado campo, seria responsável por estabelecer uma zona de tensão na experiência do cuidado, promovendo também a alteridade e a consideração das especificidades de cada categoria profissional.

No grupo focal com os tutores, o termo perfil foi utilizado para sinalizar que a formação do residente para atender as expectativas do trabalho em saúde mental depende de um processo subjetivo. A dimensão subjetiva está relacionada às características e às disposições individuais do sujeito, do envolvimento pessoal e da mobilização emocional que as experiências vivenciadas são capazes de provocar em cada um dos envolvidos. A importância do desenvolvimento dessa nova dimensão fica evidente nos seguintes repertórios interpretativos, fruto do grupo focal com os tutores ( $\mathrm{T}$ ), dos quais se destacaram as narrativas do de Ciências Sociais (T1), da de Serviço Social (T2) e a de Psicologia (T3):

\begin{abstract}
A gente vai ter que pensar em campo, núcleo e perfil. Eu acho que varia muito. (...) Então eu acho que, pra mim, não tem dúvida nenhuma que as seis áreas que a gente tem aqui têm contribuições como núcleos dentro do campo da saúde mental. Agora acho que também depende muito do indivíduo e do que ele tem pra trazer" (T1/ cso, grupo focal (GF), 14/05/09) Tem uma coisa que você (T1/ Cso) falou do perfil que eu fiquei aqui pensando também, eu acho que a gente tem vivenciado aqui, que é a questão subjetiva, mesmo, assim, da emoção, de quanto o contato com essa realidade tem mexido com o subjetivo de cada um e quanto isso tem interferido na prática delas. Eu acho que esse é um elemento-surpresa que a gente não tem como (...) tá prevendo, né?" (T2/ass., GF, 14/04/09). Eu acho que o perfil é fundamental. (...) Eu concordo com (T1/Cso) que essa questão do campo e do núcleo não é suficiente pra dar conta da complexidade do que acontece na prática. Eu acho que o perfil é um fator muito forte, agora esse perfil é tanto... toca muito na questão da subjetividade, mesmo (T3/psi., GF, 14/04/09)
\end{abstract}

O conjunto dos repertórios interpretativos dos próprios residentes e dos tutores que pode ser relacionado à noção de perfil para a atuação em saúde mental seriam: "estar disponível", "aberto", revelando protagonismo, 
autonomia, abertura para o acaso e para o encontro com o usuário. Além disso, enfatiza ser afetado emocionalmente, ser tocado por algo relativo à dimensão subjetiva, que remete a processos singulares, embora, seja necessário ressaltar, os processos singulares sejam também produzidos em contextos compartilhados pelo coletivo dos residentes, no cotidiano de trabalho e de preceptoria e de tutoria. O componente subjetivo do perfil pode relacionar-se à possibilidade de ruptura com as formas de subjetivação pelo trabalho que fixam o trabalhador como mero reprodutor de práticas já estabelecidas, não permitindo inovar, que poderia mediar o cuidado pretendido (Simoni, 2007).

\section{Considerações finais}

Os resultados obtidos por meio deste estudo mostram como a formação em serviço, a partir da organização do trabalho em equipes multiprofissionais, pode ser rica e desafiadora para o cuidado em saúde mental. As experiências multiprofissionais podem favorecer a integralidade da saúde e fomentar a qualificação dos residentes na perspectiva de desenvolverem uma postura transdisciplinar (Almeida-Filho, 1997).

A residência estudada apresenta espaços de aprendizagem para reflexão, interação e problematização das práticas, que ilustram a metodologia da educação, na direção apontada por Fagundes (2006). Percebemos que tanto a interação multiprofissional no trabalho, os momentos complementares de tutoria e a preceptoria local quanto a experiência no campo cotidiano da saúde mental levariam à respectiva diferenciação e refinamento de habilidades dos núcleos profissionais compatíveis com as necessidades do campo da saúde mental. No caso das residentes-psicólogas, o contato com a diversidade de saberes e práticas proporcionado pelo ingresso na residência multiprofissional pode levar a maior reconhecimento do seu núcleo profissional específico e contribuir para o alcance da maturidade profissional exigida pelo campo. A formação multiprofissional, nos moldes apresentados, tem potencial para o desenvolvimento de sujeitos operadores da ciência, com atitudes transdisciplinares. Para tanto, é preciso estar atento à dimensão subjetiva da formação técnico-acadêmicomilitante, que diz respeito à experiência singular de cada residente de atribuir sentidos e significados às ações que desenvolve sobre uma determinada problemática, quiçá mais próxima da compreensão de objetos complexos e orientada pela gestão de processos de mudança de si mesmos e dos entornos. 


\section{Mônica Lima}

Psicóloga, Mestra e Doutora em Saúde Coletiva pelo Instituto de Saúde Coletiva (ISC) da Universidade Federal da Bahia (UFBA), Professora Adjunto II do Instituto de Psicologia da UFBA, Pesquisadora do Núcleo Interdisciplinar em Saúde Mental do ISC da UFBA e do Laboratório de Estudos de Vínculos e Saúde Mental (LEV/IPS).

E-mail: molije@hotmail.com

\section{Lívia Santos}

Psicóloga (IPS/UFBA), Bolsista de Iniciação Científica da UFBA (PIBIC/FAPESB).

E-mail: livesantos@yahoo.com.br

Endereço para envio de correspondência:

Instituto de Psicologia da Universidade Federal da Bahia (UFBA) - Estrada de São Lázaro, 198 - Federação, Salvador, BA. CEP: 40210-730.

Recebido 16/12/2010, 1a Reformulação 4/9/2011, Aprovado 15/10/2011. 


\section{Referências}

Almeida-Filho A. (1997). Transdicisplinaridade e saúde coletiva. Ciên. Saúde Coletiva, 11(1/2)

Bastos V., \& Achcar R. (1994). Dinâmica profissional e formação do psicólogo: uma perspectiva de integração. In Conselho Federal de Psicologia. Psicólogo brasileiro: práticas emergentes e desafios para a formação (2a ed., pp. 245-271). São Paulo: Casa do Psicólogo.

Bastos, V., Gondim, S., \& Rodrigues, A. (2010). Uma categoria profissional em expansão: quantos somos e onde estamos? In A. Bastos, \& S. Gondim, (Orgs.), O trabalho do psicólogo brasileiro (pp. 32-44). Porto Alegre: Artmed.

Boing, E., \& Crepaldi, M. (2010). O psicólogo na atenção básica: uma incursão pelas políticas públicas de saúde brasileiras Psicol.: Ciênc. e Prof., 30(3), 634-649.

Brasil, Ministério da Saúde, \& Ministério de Educação e Cultura. (2006). Residência multiprofissional em saúde: experiências, avanços e desafios. Brasília, DF: Ministério da Saúde.

Campos, G. (2000). Saúde pública e saúde coletiva: campo e núcleo de saberes e práticas. Ciência e Saúde Coletiva, 5(2), 219-230.

Carvalho, L., Bosi, M., \& Freire, J. (2009). A prática do psicólogo em saúde coletiva: um estudo no município de Fortaleza (CE), Brasil. Psicol.: Ciênc. e Prof., 29(1), 60-73.

Ceccim, R. (2005). Equipes de saúde: a perspectiva entredisciplinar na produção de atos terapêuticos. In R. Pinheiro, \& A. Mattos, (Orgs.), Cuidado: as fronteiras da integralidade (259-278). Rio de Janeiro: CEPESC, UERJ, ABRASCO.

Clemente, A., Mattos, D., Grejanin, D., Santos, H., Quevedo, M., \& Massa, P. (2008). Residência em saúde da família e a formação de psicologia para a atuação na atenção básica. Saúde Sociedade, 17, 176-184.

Dallegrave, D., \& Kruse, M. (2009). No olho do furacão, na ilha a fantasia: a invenção da residência multiprofissional em saúde. Interface, 13(28), 213-237.

Fagundes S. (2006). Águas da pedagogia da implicação. Intercessões da educação para a política pública de saúde. Tese de doutorado, Universidade Federal do Rio Grande do Sul, Programa de Pós-Graduação em Educação, Porto Alegre, RS

Geertz, C. (1989). A interpretação das culturas. Rio de Janeiro: LTC.

Goldberg, J. (2001). Reabilitação como processo - o centro de atenção psicossocial. In A. Pitta, (Org.). Reabilitação psicossocial no Brasil (2a ed). São Paulo: Hucitec.

Jucá, V., Lima, M., Nunes, \& M. (2008) A (re)invenção de tecnologias no contexto de centros de atenção psicossocial: recepção e atividades grupais. Mental: Revista de Saúde Mental e Subjetividade da UNIPAC, 6(11), 125-143.

Lima, M. (2005). Atuação Psicológica Coletiva: Uma Trajetória Profissional em Unidade Básica de Saúde. Psicologia em Estudo, Maringá, 10(3) , 431-440.

Lima, M., \& Nunes, M. (2006). Práticas psicológicas e dimensões de significação dos problemas de saúde mental. Psicol.: Ciênc. e Prof., 26(2), 296-311.

Martins, C., \& Puente-Palacios, K. (2010). O psicólogo e sua inserção em equipes de trabalho. In A.Bastos, \& S. Gondim, (Orgs.), O trabalho do psicólogo brasileiro (pp. 200-22). Porto Alegre:Artmed.

Merhy, E. (2009). O ato de governar as tensões constitutivas do agir em saúde como desafio permanente de algumas estratégias gerenciais. Ciênc. Saúde Coletiva, 4(2), 305-314.

Pitta, A. (2001). Tecendo uma teia de cuidados em saúde mental. In A. Venâncio, \& M. Cavalcanti, (Orgs.), Saúde mental: campo, saberes e discursos (pp. 277- 282). Rio de Janeiro: Edições IPUB/ CUCA.

Simoni, A. (2007). A formação dos profissionais de saúde nas equipes multiprofissionais: sobre a invenção de modos de trabalhar em saúde mental. Dissertação de mestrado. Universidade Federal do Rio Grande do Sul, Porto Alegre, RS.

Spink, M. (2003). Psicologia social e saúde: práticas, saberes e sentidos. Petrópolis, RJ: Vozes.

Spink, M., \& Medrado, B. (2000). Produção de sentidos no cotidiano: uma abordagem teórico-metodológica para a análise das práticas discursivas. In M. Spink (Org.), Práticas discursivas e produção de sentidos no cotidiano: aproximações teóricas e metodológicas (2a ed., pp. 41-61). São Paulo: Cortez.

Tykanori, R. (2001). Contratualidade e reabilitação psicossocial. In A. Pitta, Reabilitação psicossocial no Brasil (2a ed, pp. 5559). São Paulo: Hucitec.

Yamamoto, O. (2003). Questão social e políticas públicas: revendo o compromisso social. In A. Bock, (Org.), Psicologia e o compromisso social (pp. 37-54). São Paulo: Cortez.

Yamamoto, O., Souza, J., Silva, N., \& Zanelli, J. (2010). In A. Bastos, \& S. Gondim, (Orgs.), O trabalho do psicólogo brasileiro (pp. 200-22). Porto Alegre: Artmed. 